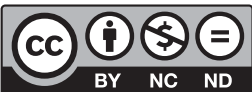

Estudos Teológicos foi licenciado com uma Licença Creative Commons Atribuição - NãoComercial - SemDerivados 3.0 Não Adaptada

http://dx.doi.org/10.22351/et.v60i1.3919

\title{
COMPROMISSO COM OS DIREITOS HUMANOS: POLÍTICAS CULTURAIS DO CANDOMBLÉ NO COMBATE AO RACISMO ${ }^{1}$
}

\author{
Commitment to human rights: \\ candomblé cultural policies in the fight against racism
}

\section{Érica Jorge Carneiro ${ }^{2}$}

\begin{abstract}
Resumo: O racismo é uma doença social e foi construído historicamente na sociedade brasileira desde o período da escravidão e da diáspora africana. Passando por teorias científicas datadas do século XIX, até sua reconfiguração por meio do mito de democracia racial, negras e negros e afrodescendentes sofrem ainda hoje de forma explícita ou velada com o racismo. Desde as décadas de 1960 e 1970, movimentos sociais, estudantis, culturais e religiosos têm se preocupado em elaborar estratégias que visem combater o racismo bem como reforçar as políticas identitárias africanas e afrodescendentes de ordem histórica, cultural e religiosa. O texto em questão aborda duas ações culturais de combate ao racismo elaboradas por um terreiro de candomblé jeje-nagô, de forma a destacar a preocupação dessa religião com a preservação dos direitos humanos sem declinar das especificidades étnicas, culturais e religiosas do grupo em questão.
\end{abstract}

Palavras-chave: Direitos Humanos. Racismo. Candomblé. Política cultural.

Abstract: Racism is a social disease and has been built historically in Brazilian society since the period of slavery and the African diaspora. Going through scientific theories dating from the 19th century, until its reconfiguration through the myth of racial democracy, blacks and afro-descendants suffer today explicitly or veiled with racism. Since the 1960s and 1970s, social, student, cultural and religious movements have been concerned with developing strategies aimed at combating racism as well as strengthening African identities and African policies of historical, cultural and cultural Religious. This paper addresses two cultural actions to combat racism prepared by an afro-Brazilian religion named candomblé, in order to highlight the concern of this religion with the preservation of human rights without declining ethnic, cultural and religious rights of the group in question.

Keywords: Human Rights. Racism. Candomblé. Cultural Policy.

1 O artigo foi recebido em 22 de março de 2020 e aprovado em 13 de abril de 2020 com base nas avaliações dos pareceristas ad hoc.

2 Doutora em Ciências Humanas e Sociais. FAITA. E-mail: ericafcj@gmail.com 


\section{Introdução}

O racismo é parte constitutiva da história brasileira. Erigido ora como crença, ora como política, ele acompanhou o processo de desenvolvimento de nossa sociedade acarretando um conjunto de consequências que até hoje se tenta reparar. Essas tentativas implicam mudanças de compreensão e de projeto de cidadania e percorrem os campos políticos, econômicos, culturais, educacionais e religiosos.

Rever a história africana, afro-brasileira e indígena em nosso país significa acompanhar a herança do colonialismo e da ideologia eurocêntrica. Ao mesmo tempo, compreender as bases fundadoras do racismo como lógicas de poder permite observar o apagamento das culturas supracitadas e, consequentemente, oferecer lente mais fidedigna aos fatos históricos. $\mathrm{O}$ eurocentrismo, a eugenia, as políticas de embranquecimento e o contexto colonialista explorador destituíram povos, culturas, memórias e identidades africanas, afrodescendentes e indígenas. É justamente sobre a compreensão desse "apagamento", suas consequências e ações efetivas de combate ao racismo que este artigo se debruça.

\section{O racismo no Brasil}

Apresento uma breve síntese de como o racismo à brasileira se erigiu e embasou políticas e práticas culturais em nosso país. Seguindo o corpo teórico especializado, organizo a síntese em quatro momentos históricos: o primeiro entre 1870 e 1930 , o segundo entre 1930 e 1950, o terceiro entre 1950-1970 e, finalmente, o quarto de 1970 até os dias atuais.

\section{De 1870 a 1930: as teorias cientificas do século XIX}

O século XIX foi decisivo para a história das relações sociais no Brasil. Mas a história dos encontros culturais começa antes. Desde o século XVI, período do achamento do Brasil, os índios foram utilizados como mão de obra escrava para Portugal. Inadaptados ao trabalho, iniciou-se a substituição da mão de obra indígena pela africana. A Transatlântica, uma das três rotas utilizadas para o tráfico de escravos (e aquela que os trouxe ao Brasil), fez com que negros de etnias variadas aqui chegassem em situação de sujeição de seus corpos. Portanto, embora o século XIX tenha sido decisivo porque institucionalizou e difundiu cientificamente a ideia de civilizações inferiores e superiores, a história é pregressa e data do século XVI.

No século XIX, o Brasil que pretendia se alçar à nação moderna se via com um "problema" a resolver: a questão racial ${ }^{3}$. Acreditava-se que os negros eram inferiores biologicamente e que o contato com a população branca poderia degenerar as gerações seguintes. $\mathrm{O}$ argumento racial foi política e historicamente construído, do mesmo modo que o conceito de raça recebeu, além de sua interpretação racial, um viés

3 ROMERO, Silvio. Introdução à história da Literatura Brasileira. Rio de Janeiro: Nacional, 1882. 
social. A elite brasileira da época, ao consumir a literatura europeia, passou a reproduzir diferentes modelos, mas todos de mesmo propósito: reforçar o estabelecimento de diferenças sociais. Do darwinismo social, ao atribuir o caráter "forte" e "fraco", adotou-se a ideia de que as sociedades mais organizadas e evoluídas se perpetuariam, ao passo que as demais tenderiam a extinguir-se. Do evolucionismo social, a ideia de que as sociedades fariam parte de uma linha única de evolução, mas que estariam em estágios diferentes e, portanto, evoluiriam do simples ao complexo. Os "homens de sciencia"4, cientistas, políticos, pesquisadores, intelectuais e literatos herdaram e adaptaram as teorias europeias à realidade brasileira, à época com uma população afrodescendente maior que a branca. A criação das faculdades de Medicina e Direito, de museus e institutos históricos ofereceu estrutura institucional para legitimar o racismo. Assistiu-se, então, à correlação entre a produção científica (as diversas teorias científicas) e a dinâmica social.

\section{De 1930 a 1950: a primeira geração das relações raciais}

A década de 1930 representou uma mudança significativa para os estudos sociais no Brasil. É a partir desse período que a categoria raça associada à biologia perde força e é substituída pela cultura. O pensamento social brasileiro era formulado com os estudos na área de sociologia, antropologia e mesmo da literatura. Os estudos de Franz Boas foram consumidos no Brasil e ajudaram a configurar um movimento em favor do culturalismo, e as sociedades consideradas primitivas passaram a ser observadas de uma outra perspectiva.

Na esteira desse pensamento, Gilberto Freyre publicou "Casa Grande e Senzala", obra que trata da formação do povo brasileiro sob o regime da família patriarcal em período colonial. Embora de bastante informação histórica, ela ganhou visibilidade principalmente por apresentar uma visão bastante otimista das relações raciais no país, rompendo com a ideia anterior de que a mistura entre portugueses, indígenas e africanos traria atraso ao país (a teoria da degeneração). Freyre recusa o darwinismo social, os determinismos genético e geográfico e o próprio racismo como explicações para a configuração sociocultural do Brasil. Defende que a sociedade colonial brasileira foi forjada nas relações domésticas íntimas e assimétricas nos engenhos de açúcar e, diferentemente da abordagem segregacionista observada quando de seus estudos nos Estados Unidos, o Brasil comporia uma maneira singular de relações amistosas entre brancos e negros. Embora o termo democracia racial só tenha sido empregado pelo autor em 1962, quando Freyre se autoproclamou defensor do patriotismo brasileiro, o conceito já estava delineado nessa sua obra de $1933 .{ }^{5}$

\footnotetext{
4 SCHWARCZ, Lilia. O espetáculo das raças. Cientistas, instituições e a questão racial no Brasil. 18701930. São Paulo: Companhia das Letras, 1993.

5 GUIMARÃES, Antônio Sergio. Racismo e Anti-Racismo no Brasil. São Paulo: Editora 34, 1999.
} 
O pensamento da democracia racial dominou o pensamento sobre raça dos anos 1930 aos anos $1990^{6}$ com várias obras repercutindo a visão de que havia uma fusão serena entre as populações e culturas europeias, indígenas e africanas. Essa linha de pensamento parecia bastante aceita, principalmente dado o período anterior, que demarcava linhas bastante rígidas entre as raças em seu sentido biológico. Até a década de 1930, as políticas públicas, as instituições educacionais, sanitaristas e legalistas compactuavam com a visão de que o contato genético entre brancos, negros e indígenas seria desastroso para o futuro da nação. A mestiçagem era sinônimo de degeneração. Por isso a visão de Freyre apresentava-se como moderna não apenas cientificamente, refletindo as mudanças na antropologia, mas, igualmente, como projeto de nacionalidade que o país exigia. A visão freyreana teve fortes impactos no universo religioso afro-brasileiro.

É importante salientar que as religiões afro-brasileiras formam um universo diverso. São compostas por matrizes diferentes e acomodam-se às particularidades de cada região brasileira. Assim, embora encontremos candomblé e umbanda (as duas religiões afro-brasileiras mais cultuadas) em praticamente todos os estados do país, elas se apresentam de forma diferente entre um e outro, dado o processo de povoação e as práticas culturais assumidas em cada região. Ainda com a pluralidade existente, o mito da democracia racial, disseminado com a teoria freyreana impactou o universo afro-brasileiro como um todo. Candomblé e umbanda refutaram e incorporaram o mito, respectivamente. $\mathrm{O}$ candomblé defendeu o discurso de purismo étnico e religioso, ao passo que a umbanda se apresentou como defensora da miscigenação étnica e religiosa.

Para elucidar a proposição acima, é importante discutir, ainda que brevemente, a formação dessas religiões em solo brasileiro. Os candomblés se constituem a partir da ideia das nações. Existiram muitas etnias que vieram para o Brasil no período escravagista, mas a grande maioria dos escravos não era reconhecida pela sua etnia, senão pelo nome do porto do qual saía de alguma região da África. Assim, "chamava-se indistintamente mina a todos aqueles que passavam pelo forte de Mina, fossem achântis, jejes ou iorubas" ". Com o passar do tempo, a ideia de nação cai em desuso e os negros passam a ser chamados como negros, sem uma referência direta à sua etnia. Ele passa a ser "categorizado" como negro. Se as nações deixam de ser uma realidade para identificar os negros, isso não acontece da mesma maneira nos terreiros. Nas comunidades de candomblé, elas passam a ser valorizadas como forma de diferenciar as práticas umas das outras. Na Bahia, acentuam-se três nações para o candomblé: nagô ou iorubas, os bantos e os ewe-fons. Nos primeiros estão inseridas as etnias ketu, ijexá e efan. Nos bantos, angola, congo e cabinda e, finalmente, os ewe-fons abarcam os jejes e os jeje-mahis. Há diferenças entre essas três grandes nações, que podem ser identificadas na maneira de tocar os atabaques, nos tipos de cânticos, na dança,

6 TELLES, Edward. Racismo à Brasileira. Uma nova perspectiva sociológica. Rio de Janeiro: Relume Dumará, 2003.

7 PRANDI, Reginaldo. De africano a afro-brasileiro: etnia, identidade, religião. Revista USP, São Paulo, n. $46,2000$. 
nas preferências alimentares e nome de deuses. ${ }^{8}$ Mas há em todos eles um elemento fundamental: a organização social do terreiro em torno da família de santo, a qual irá, inicialmente, recriar a África. ${ }^{9}$ Os grupos de candomblés que foram criados em seu princípio configuravam um espaço geográfico de rememoração da África e os seus conteúdos culturais foram, de alguma maneira, recriados no dia a dia do terreiro. Mas a organização das famílias de santo assim como a adoração a vários orixás no mesmo terreiro é uma criação brasileira.

Se os autores clássicos tinham o candomblé como uma religião africana ou de sobrevivências religiosas africanas ${ }^{10}$, os autores contemporâneos enxergam o candomblé como uma religião brasileira. Por exemplo, "o candomblé é a religião brasileira dos orixás" "Africanizar ou desafricanizar sempre foi uma pauta importante dentro do universo do candomblé.

Diferentemente, a umbanda sempre se colocou como a religião genuinamente brasileira e de certa forma incorporando os pressupostos da democracia racial de Freyre, aplicados à religião. Entendida e apresentada como religião brasileira, a umbanda se desenvolve especialmente na década de 1930, período esse que se vincula às teorias e formulações raciais em prol de uma mestiçagem afável e bem resolvida. Negando o viés kardecista ${ }^{12}$, líderes e grupos de classe média passam a cultuar uma umbanda diferente, a qual não negava, mas, ao contrário, passou a cultuar espíritos de ancestrais brancos, pretos e indígenas. Por seu poder de atuação especialmente em São Paulo, a partir da década de 1930 essa umbanda se dissemina e institucionaliza a religião alinhando-a ao projeto político-cultural nacionalista de Vargas. ${ }^{13}$

A institucionalização da umbanda, a partir da criação de federações, foi um reflexo do processo de mudança pela qual passa a sociedade brasileira [...] a preocupação em edificar uma religião centrada na possibilidade de manifestação de espíritos oriundos das três etnias que formam a nação brasileira, foi certamente influenciada pelo intenso nacionalismo do regime de Vargas e pelo esforço de criar uma cultura nacional como base para a unificação do povo brasileira. ${ }^{14}$

A história das três raças formadoras da nação e da mestiçagem redentora encontra ampla ressonância nas ciências sociais, na literatura e no discurso político vigente.

8 BASTIDE, Roger. O Candomblé da Bahia. São Paulo: Cia das Letras, 2001.

9 SILVA, Vagner Gonçalves. Candomblé e Umbanda. Caminhos da devoção brasileira. São Paulo: Selo Negro, 2005.

10 VERGER, Pierre. Lendas dos Deuses Africanos. Bahia: Corrupio, 1992.

11 PRANDI, Reginaldo. O Brasil com axé: candomblé e umbanda no mercado religioso. Estud. av., São Paulo, v. 18, n. 52, p. 223-238, dez. 2004.

$12 \mathrm{O}$ espiritismo de umbanda considerava que havia um evolucionismo entre os espíritos de modo que os espíritos de indígenas e africanos deveriam ser ensinados e "adestrados” pelos espíritos mais evoluídos.

13 BIRMAN, Patrícia. O que é umbanda. São Paulo: Abril Cultural; Brasiliense, 1985. GIUMBELLI, Emerson. "Zélio de Moraes e as origens da umbanda no Rio de Janeiro". In: SILVA, V. G. (Org.). Caminhos da alma: memória afro-brasileira. São Paulo: Summus, 2002. p. 183-217.

14 OLIVEIRA, José Henrique Mota de. Das macumbas à umbanda: uma análise histórica da construção de uma religião brasileira. Limeira: Editora do Conhecimento, 2008. 
E foi ancorada nessa linha que a umbanda se erigiu e igualmente se diferenciou do candomblé. Até hoje, embora o candomblé tenha se universalizado aos moldes weberianos, seu engajamento à pauta racial é bastante diferente do pensamento umbandista.

\section{De 1950 a 1970: a segunda geração das relações raciais}

A década de 1950 é importante para o estudo das relações raciais no Brasil. Até então, vigorava a ideologia de democracia racial, cujas relações, sobretudo entre brancos e negros, dar-se-iam em termos harmoniosos. Mas, em 1950, preocupada em entender o modelo multirracial exitoso brasileiro, principalmente diante dos horrores da guerra e do genocídio racial, a Unesco encomenda uma série de pesquisas a estudiosos brasileiros. Assim, Florestan Fernandes em São Paulo e seus colegas começam uma adensada análise e concluem que o Brasil não tinha a marca segregacionista tais como os países Estados Unidos e África do Sul, mas havia um racismo de consequências devastadoras aos afrodescendentes. A pesquisa desmontou o mito da democracia racial e passou a guiar os estudos que se seguiram. Em síntese, a primeira geração postulava a democracia racial brasileira enquanto a segunda a refutava.

Do ponto de vista político, em 1951 a Lei Afonso Arinos tornou o racismo ilegal e punível. ${ }^{15}$ Em 1958, o Brasil ratificou a Convenção da Organização Internacional do Trabalho sobre discriminação em matéria de emprego e ocupação. Assim como, dez anos depois, foi assinada a Convenção Internacional para Eliminação de Todas as Formas de Discriminação Racial (ICERD).$^{16}$

A segunda geração dos estudos raciais foi extremamente importante para delinear academicamente a existência do racismo. Porém a crença na mestiçagem como algo positivo, a visão do Brasil como um país multirracial afetuoso vigorava no senso comum, na mídia e na política.

De 1964 a 1970, enquanto o governo militar consolidava seu poder autoritário, os estudos raciais que haviam imprimido avanço em âmbito acadêmico foram cerceados. Eles representavam uma ameaça à ideologia da unificação nacional, uma vez que desmascaravam as inconsistências do discurso da mestiçagem positiva e revelavam as violências sociais, sobretudo, dos negros. Por isso muitos autores da área foram exilados. Abdias do Nascimento, Florestan Fernandes, Fernando Henrique Cardoso, Octávio Ianni são exemplos dos que questionaram o consenso nacionalista sobre raça ${ }^{17} \mathrm{e}$ tiveram suas pesquisas impedidas. No período ditatorial, a ideia de democracia racial e a apresentação da mestiçagem como característica da brasilidade eram consoantes à identidade nacionalista em voga. Qualquer estudo ou posicionamento que insuflasse posicionamento oposto deveria ser extirpado.

15 MITCHELL, Michael. Anti-Discrimination Litigation and Judicial Reform in Brazil. Paper presented at the American Political Science Association meetings. Boston: August, 2002.

16 BANTON, Michael. Racial Theories. London: Cambridge University Press, 1998.

17 SKIDMORE, Thomas. Preto no Branco. Raça e nacionalidade no pensamento brasileiro. Rio de Janeiro: Paz e Terra, 1976. 


\section{Ações efetivas de combate ao racismo: a festa "A Corte dos Orixás" e a "Exposição Anual da Consciência Negra"}

Os estudos da segunda geração foram decisivos para a revisão do pensamento sobre as relações raciais no país e causaram impactos nas universidades, com o surgimento de linhas de pesquisa sobre a pauta racial e identitária, nas instituições culturais e movimentos sociais, como, por exemplo, o Teatro Experimental Negro, o fortalecimento do Movimento Negro e, igualmente, impactaram o universo religioso.

As religiões afro-brasileiras são, por sua natureza, aquelas cujos adeptos mais sofreram com o racismo de cor e com o racismo religioso. Chauí18, ao argumentar sobre a violência na imaginação social brasileira, afirma que ela está fundada em uma máquina mitológica centrada em cinco elementos discursivos: o primeiro é o da não violência, o segundo é da distinção, o terceiro elemento é jurídico. O quarto elemento é sociológico e o quinto é o da inversão real. Os cinco elementos são importantes pontos reflexivos acerca da incorporação da violência racial e do racismo religioso como hábito, como sugere Bourdieu ${ }^{19}$.

O primeiro argumento da "máquina mitológica" entende a sociedade brasileira como pacífica, mestiça e cordial, de modo a não perpetuar violências, como foi possível observar com o discurso da democracia racial da década de 1930, incorporado na política e na religião (no caso, a umbanda). O segundo diferencia o essencial do acidental. Em acordo com o argumento anterior, como a sociedade é entendida como não violenta, qualquer ato de violência será lido como um mero acidente, não exigindo estratégias políticas de combate, sendo essas públicas ou não. O terceiro argumento de tipo jurídico associa diretamente a violência ao campo da delinquência e criminalidade, de tal forma que práticas de violência não tão perceptíveis tornam-se invisibilizadas ou até mesmo naturalizadas. O quarto argumento é de tipo sociológico, considerando que a violência está restrita a um período histórico. No caso do debate racial, isso fica muito evidente, pois as pessoas no senso comum, e mesmo em discursos políticos, assumem que a violência do racismo estava restrita à política escravagista e, com o seu fim, os afrodescendentes teriam conquistado naturalmente sua inserção e direitos. Por fim, o último mecanismo é o da inversão do real. São formas de atuação em sociedade dissimulando comportamentos, ideias e valores violentos como se fossem não violentos. No que se refere ao racismo, tem-se como exemplo a defesa dos brancos sobre a meritocracia descreditando qualquer política pública de cunho racial ou ainda seu paternalismo visto como proteção para auxiliar os negros.

Os elementos levantados por Chauí acima indicam uma maneira de pensar que é do senso comum, da "imaginação social", mas foi também produzida por intelectuais, cientistas sociais, literatos, sanitaristas e políticos por muitas gerações e se refletiram no atraso na formulação de políticas públicas de ações afirmativas, bem como perpetuaram um modo de estar no mundo em conivência às violências de cor e do racismo religioso.

${ }^{18}$ CHAUÍ, Marilena. Cultura política e política cultural. Estud. av., São Paulo, v. 9, n. 23, p. 71-84, 1995.

${ }^{19}$ BOURDIEU, Pierre. O poder simbólico. Rio de Janeiro: Bertrand Brasil, 2003. 
No Brasil, dada a história de violência aos povos afrodescendentes, são recentes os dispositivos legais que configuram o racismo como crime e, ainda assim, há bastante incompreensão sobre o assunto. Por exemplo, há diferentes tipos penais nos quais o exercício de racismo pode ser enquadrado: como injúria qualificada por preconceito (ser for entendido que somente a honra subjetiva de uma única pessoa foi atingida) ou racismo (se for aceito pelo sistema judiciário que uma prática específica gerou dolo para todos os negros).$^{20} \mathrm{O}$ racismo religioso torna-se ainda mais difícil de ser lido, uma vez que as camadas de compreensão passam por duas questões: a cor e a religião. Nesse sentido, concordando com a filósofa Marilene Chauí, as práticas de violência alicerçadas no preconceito (e até mesmo no ódio) continuam, pois somam-se à máquina mitológica a incompreensão sobre a lei do racismo e suas consequências, tanto para quem pratica quanto para quem sofre. Outro elemento importante é sobre a naturalização da violência com os terreiros afro-brasileiros. Dados recentes reforçam que são essas comunidades as mais impactadas. ${ }^{21}$

Já foi demonstrado no texto o processo de construção histórica e ideológica do racismo em nosso país. Especialmente, desde o século XIX, os afrodescendentes que se articulam em torno de uma família de santo sofrem as violências de cor, as quais se enredam aos preconceitos religiosos, associando as matrizes africanas ao exótico e ao perigo. Assim, no espectro quantitativo, as populações religiosas afrodescendentes são vítimas incontestavelmente majoritárias de agressões físicas, morais e simbólicas. Qualitativamente, os meios pelos quais são perpetradas tais violações sinalizam uma truculência, sistematicidade e coordenação que inserem a problemática no campo estrutural do racismo e da supressão de direitos..$^{22}$

O universo de violência e o atraso na formulação de políticas públicas para minimizar o racismo fizeram com que muitas comunidades religiosas afro-brasileiras se organizassem e estabelecessem estratégias de combate ao racismo (de cor e religioso) na justa medida em que protegiam seus membros. Assim, optei no artigo por destacar duas ações efetivas de combate ao racismo elaboradas pelo terreiro Ile Funfun Ase Awoosogun, localizado no litoral paulista, o qual já pesquiso desde meu doutorado. A primeira ação foi a criação da festa "A Corte dos Orixás" e a segunda a "Exposição Anual sobre Racismo", a qual se encerra com a publicação de um livro sobre o tema.

${ }^{20}$ SANTOS, Gisleine Aparecido dos. Nem crime, nem castigo: o racismo na percepção do judiciário e das vítimas de atos de discriminação. Revista do Instituto de Estudos Brasileiros, Brasil, n. 62, p. 184-207, dez. 2015.

${ }^{21}$ FONSECA, Alexandre Brasil; ADAD, Clara Jane (Orgs.). Relatório sobre intolerância e violência religiosa no Brasil (2011 - 2015): resultados preliminares / Ministério das Mulheres, da Igualdade Racial, da Juventude e dos Direitos Humanos. Brasília: Secretaria Especial de Direitos Humanos, SDH/PR, 2016.

22 HOSHINO, Thiago de Azevedo Pinheiro; CHUEIRI, Vera Karam de. As cores das/os cortes: uma leitura do RE 494601 a partir do racismo religioso. Rev. Direito Práx., Rio de Janeiro, v. 10, n. 3, p. $2.214-$ 2.238, 2019. 
A festa "A Corte dos Orixás" foi idealizada por Francisco Rivas Neto, então sacerdote do terreiro no ano de 2016. A proposta é pautada na experiência democrática, configurando-se como uma festividade de rua e recuperando a importância de eventos culturais abertos aos cidadãos.

A festa é pública, liberada sob ofício pela prefeitura da cidade, e não há taxa alguma de recolhimento de ingresso. Durante todo o dia, os membros do terreiro organizam-se em barracas variadas: culinária afro-brasileira, literatura afro-brasileira, barraca de ervas, flores, chás e defumações, performances de danças dos variados ritmos africanos e indígenas, oficina de arte africana. Além disso, são convidados artistas e grupos de música e dança africana e afro-brasileira para se apresentarem e comporem a programação que se estende até o final do dia.

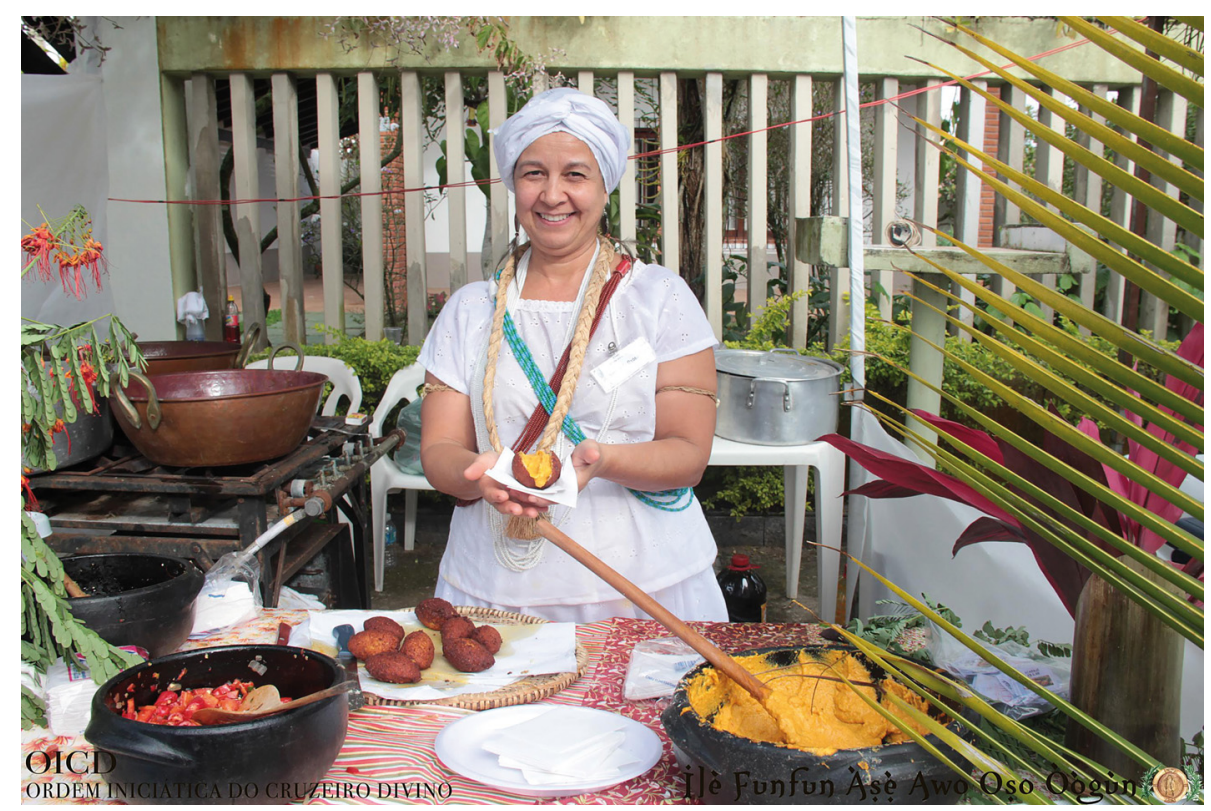

Foto 1. Barraca do Acarajé

A festa recebeu esse nome em homenagem a uma pintura que uma das filhas de santo fez na parede principal do terreiro e que foi inaugurada no dia da primeira festa. A tela retrata a "Corte dos Orixás", o desenho de um trajeto honroso das divindades do panteão jeje-nagô. Nela é possível observar Ogun, o deus do ferro e da agricultura; Oxossi, o deus da caça; Xangô, o deus da justiça; Omulu, o deus da saúde; Oxalá e Nanã, as divindades da criação, da paciência e da sabedoria. Veem-se também Oyá, a senhora dos ventos e da força; Yemanjá, a rainha do mar; Oxum, a senhora da doçura e da magia. 


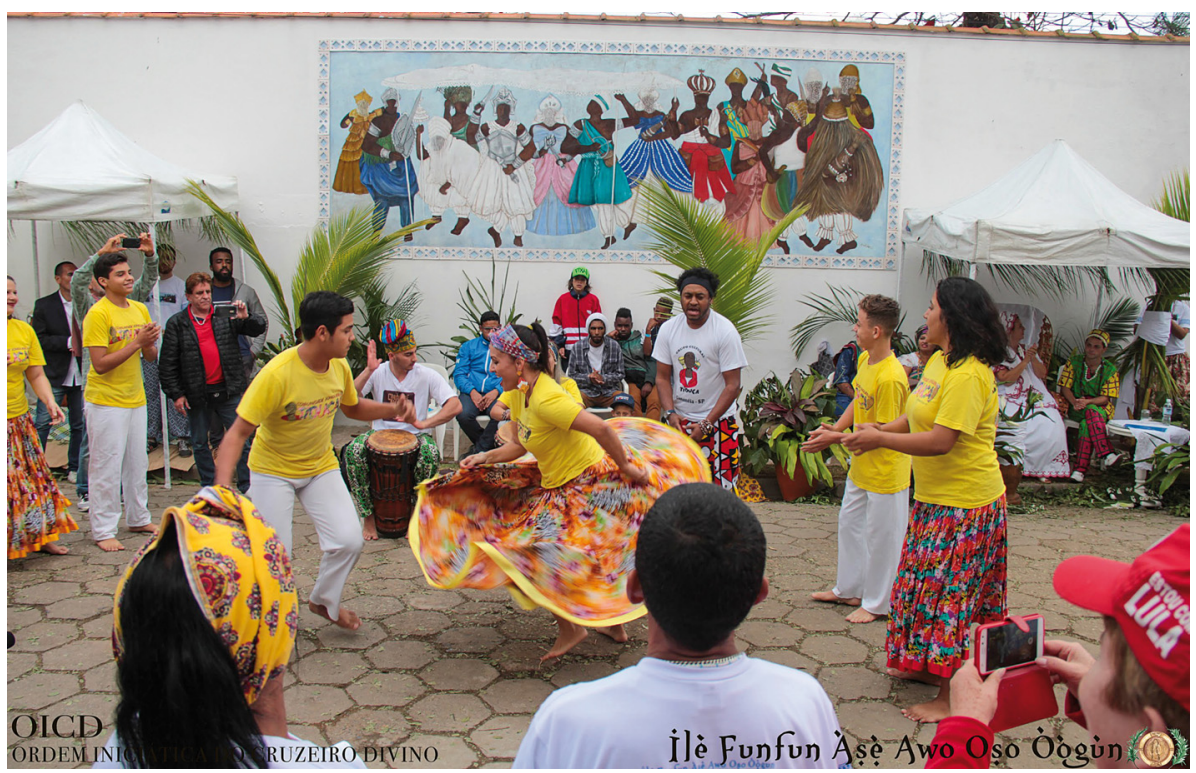

Foto 2. Pintura "A Corte dos Orixás"

O nome da pintura foi estendido à festa representando a concretização dos princípios dos Orixás, forças da natureza que oferecem ao mundo uma proposta de vida não eurocêntrica e ocidental e que resgata a relação do ser humano com sua ancestralidade, com sua natureza divina e com a natureza planetária.

Partindo da ideia de que o racismo se constitui como uma doença social, felizmente considerado hoje crime, a festa visa oferecer um ambiente agradável de valorização da história, da arte e da cultura africana e afro-brasileira. Ela congrega grupos religiosos afro-brasileiros, mas a proposta não é de captação de adeptos ou reforço da identidade específica do terreiro envolvido (até porque não acontece nenhum ritual religioso), ao contrário, é um evento já estabelecido no calendário da cidade extraoficialmente - dado o sucesso obtido - como divulgador da história e da cultura afro-brasileira. Cabe ressaltar que a festa não recebe parcela de ajuda pública para sua realização, como o empréstimo de mesas e cadeiras, mas sem qualquer valor pecuniário. Os gastos com a organização e realização são arrecadados pelos membros da família de santo meses antes, bem como o valor acumulado (com a venda de alimentos e ou outros produtos) são revertidos para o pagamento de artistas e aluguel de materiais de som. 


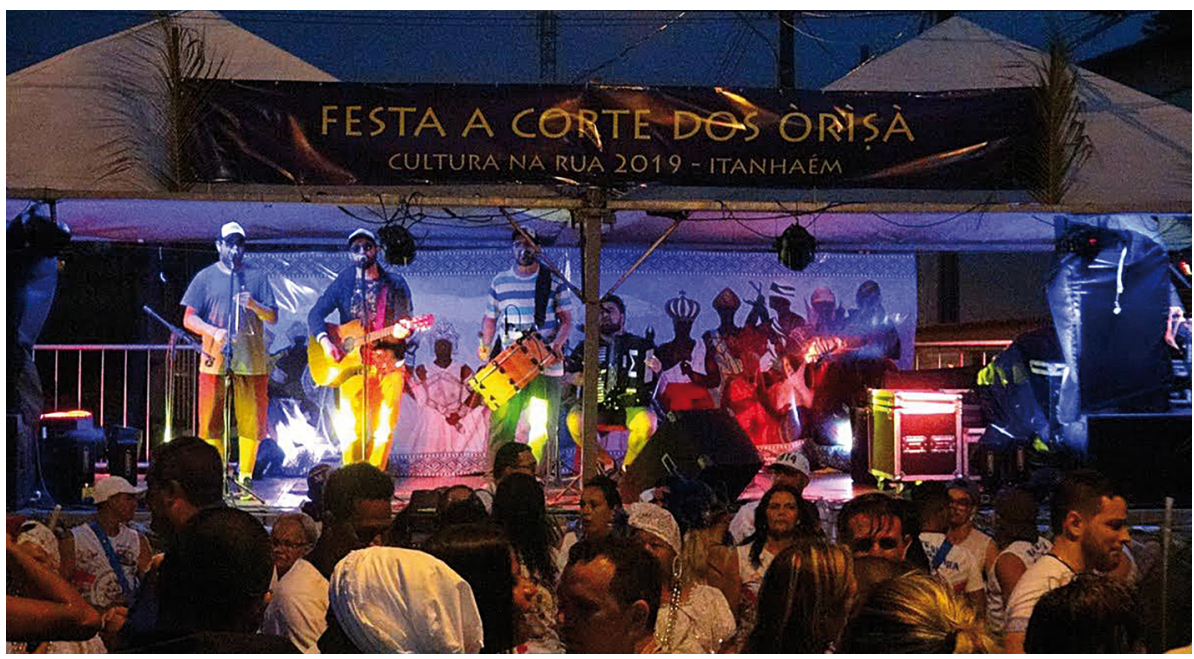

Foto 3. Palco principal da Festa "A Corte dos Orixás"

Até o momento foram realizadas três edições da festa. Sendo as duas últimas já sob orientação da Iyá Maria Elise Rivas - Bê T'Xangô -, quem assumiu o comando do terreiro após o falecimento de seu esposo, Babá Rivas T'Oguian.

A festividade criada pelo terreiro atende várias demandas da própria cidade como a criação de evento cultural (com alimentos, danças e artefatos específicos da cultura negra), a divulgação da pauta racial de modo que os munícipes percebam que o tema tem sido trabalhado para além da esfera educacional, a disseminação de um discurso em prol do pacifismo e do respeito inter-religioso. A festa tem rendido discussões acirradas não apenas durante o seu acontecimento, mas sobretudo nas redes sociais. Desde a divulgação do evento até dias após o ocorrido quando fotos e publicações são realizadas, a festividade é bastante comentada e consequentemente a pauta do combate ao racismo de viés étnico e religioso.

\section{A Exposição Anual de Combate Ao Racismo}

Outro evento muito esperado na cidade é a "Exposição Anual de Combate ao Racismo", realizada pelo mesmo terreiro e que ocorre nas dependências do Fórum Municipal de Itanhaém.

A proposta do ilê, nome esse atribuído também às casas de candomblé no Brasil, surgiu como iniciativa prática para o debate acerca do racismo durante a Semana da Consciência Negra. O dia 20 de novembro foi destacado como um marco no debate sobre o racismo. A visão mais conservadora sobre as relações raciais em nosso país considera que a data serve apenas para reiterar uma perspectiva segregacionista. Por outro lado, aqueles que compreendem a violência causada aos negros desde a época da escravidão e se identificam com sua luta, entendem que há necessidade de datas, eventos e políticas públicas que trabalhem pela valorização da história, cultura, arte e 
religiosidade africanas e afro-brasileiras. É esse o caso do terreiro em questão, o qual se identifica como herdeiro da tradição religiosa africana, mas, sobretudo, por entender que nenhuma vida humana merece ser desrespeitada, vilipendiada e excluída socialmente.

Nesse sentido, a mãe de santo do Ilê Funfun Ase Awosogun, Mãe Maria Elise Rivas, cujo nome religioso é Iyá Bê de Xangô, concebeu o projeto da exposição anual. A primeira exposição ocorrida em 2018 foi nomeada "Os (In)Visibilizados" e contou com instalação física de banners, à entrada do Fórum da Comarca de Itanhaém, de personagens da história brasileira que contribuíram em frentes variadas, como música, literatura, ciência etc., alguns pouco conhecidos e outros mais notórios, apesar de a história não os retratar como negros ou apagar tal caraterística. São eles: Luiz Gama, Machado de Assis, Chiquinha Gonzaga, Castro Alves, Rui Barbosa, Pedro Lessa, Nina Rodrigues, João do Rio, Lima Barreto, Donga, Antonieta de Barros, Carybé, Carolina de Jesus, Milton Santos, Sueli Carneiro e F. Rivas Neto. Cada banner, além da imagem, trazia breve biografia de cada personagem. Ainda no espaço foi montado um painel interativo, com exibição de fotografias dos visitantes junto aos banners. Integrou ainda o projeto um "ciclo de palestras", realizadas na Pinacoteca Municipal. As palestras abordavam temas variados como: (1) Crianças de terreiro: redes de afeto e aprendizagem; (2) Filosofia e ética africanas; (3) Contação de histórias negras; (4) Balanço sobre a Lei 10.639/03 - Ensino de história e cultura africanas nas escolas; e (5) Arte! Literatura e música negras no Brasil.

A segunda exposição ocorrida em 2019 foi nomeada "Violência em Cores". Nela, o objetivo foi apontar as principais consequências do racismo na sociedade brasileira. Para tanto, foram confeccionados, pelos filhos de santo do terreiro, painéis que tratavam sobre: intolerância religiosa, violência doméstica, a desigualdade do sistema penitenciário e jurídico brasileiro, a língua e literatura como produtoras de racismo e os problemas da disseminação do mito da democracia racial.

As exposições ocorrem sempre no Fórum da Comarca de Itanhaém e contam com o apoio da juíza de Direito Helen Cristina de Melo Alexandre e da Prefeitura da cidade de Itanhaém. Além das fotos, banners, ciclo de palestras, o projeto conta ainda com a publicação de um livro sobre o tema, o qual recebe o nome da exposição em questão. O primeiro livro "Os (In)Visibilizados" reuniu as informações e explicações sobre os personagens históricos apresentados na exposição. O segundo livro, "Violência em Cores", optou por uma abordagem diferenciada. Foram convidados professores doutores para discorrer sobre o racismo sob a perspectiva acadêmica. Também foram convidados negros e negras praticantes das religiões afro-brasileiras que escreveram textos-relatos contando como o racismo influenciou e marcou suas experiências de vida. O livro atrelou, portanto, o olhar científico e a experiência sentida de quem realmente sente o racismo diariamente na sociedade brasileira.

\section{Considerações finais}

O racismo é uma doença social constitutiva da sociedade brasileira. Durante o século XIX, o Brasil herdou as teorias disseminadas na Europa que justificavam o ra- 
cismo cientificamente. Já nas primeiras décadas do século XX, elas tornaram-se obsoletas, de modo que em seu lugar passa a ser trabalhada a categoria cultura e não mais a raça. No entanto, a perspectiva de segregação racial e da não incorporação dos negros à sociedade moderna (já distanciada legalmente do sistema escravocrata) perdurou, de modo que hoje falamos em racismo de cor, racismo religioso e racismo social, todos eles são formas violentas de exclusão e que se manifestam explicitamente ou de formas veladas. Desde a década de 1960, movimentos sociais, movimentos estudantis, culturais e religiosos começaram a se organizar e a propor políticas de combate ao racismo. No artigo em questão, destaquei dois projetos elaborados e realizados pelo terreiro de candomblé Ile Funfun Ase Awosogun. A mantenedora religiosa do terreiro, chamada Ordem Iniciática do Cruzeiro Divino, atua desde 1970 com projetos de saúde e educação prestando acolhimento e orientação às pessoas. Uma vez que a pauta do racismo tornou-se cada vez mais urgente, esse terreiro de candomblé jeje-nagô, dirigido pela Iyá Maria Elise Rivas, resolveu ampliar suas ações para além de uma questão religiosa, mas entendendo que é um dever de qualquer cidadão brasileiro (e, no caso, religioso) defender condições humanas, justas, democráticas e equânimes de tratamento às pessoas. $\mathrm{O}$ candomblé, religião brasileira de matriz africana, tem se preocupado em fazer força à luta contra o racismo, unindo-se a outros movimentos. Os projetos analisados no artigo são exemplos de como a religião pode e deve criar esforços para assegurar os direitos humanos, ao mesmo tempo respeitando as especificidades identitárias e culturais dos grupos afins.

\section{Referências}

BANTON, Michael. Racial Theories. London: Cambridge University Press, 1998.

BASTIDE, Roger. O Candomblé da Bahia. São Paulo: Cia das Letras, 2001.

BIRMAN, Patrícia. O que é umbanda. São Paulo: Abril Cultural; Brasiliense, 1985.

BOURDIEU, Pierre. O poder simbólico. Rio de Janeiro: Bertrand Brasil, 2003.

CHAUÍ, Marilena. Cultura política e política cultural. Estud. av. São Paulo, v. 9, n. 23, p. 7184, 1995.

FONSECA, Alexandre Brasil; ADAD, Clara Jane (Orgs.). Relatório sobre intolerância e violência religiosa no Brasil (2011- 2015): resultados preliminares / Ministério das Mulheres, da Igualdade Racial, da Juventude e dos Direitos Humanos. Brasília: Secretaria Especial de Direitos Humanos, SDH/PR, 2016.

GIUMBELLI, Emerson. “Zélio de Moraes e as origens da umbanda no Rio de Janeiro”. In: SILVA, V. G. (Org.). Caminhos da alma: memória afro-brasileira. São Paulo: Summus, 2002. p. 183-217. GUIMARÃES, Antônio Sergio. Racismo e Anti-Racismo no Brasil. São Paulo: Editora 34, 1999. HOSHINO, Thiago de Azevedo Pinheiro; CHUEIRI, Vera Karam de. As cores das/os cortes: uma leitura do RE 494601 a partir do racismo religioso. Rev. Direito Práx., Rio de Janeiro, v. 10, n. 3, p. 2.214-2.238, 2019.

OLIVEIRA, José Henrique Mota de. Das macumbas à umbanda: uma análise histórica da construção de uma religião brasileira. Limeira: Editora do Conhecimento, 2008.

PRANDI, Reginaldo. O Brasil com axé: candomblé e umbanda no mercado religioso. Estud. av., São Paulo, v. 18, n. 52, p. 223-238, dez. 2004.

. De africano a afro-brasileiro: etnia, identidade, religião. Revista USP, São Paulo, n. 46, 2000. ROMERO, Silvio. Introdução à história da Literatura Brasileira. Rio de Janeiro: Nacional, 1882. 
SANTOS, Gisleine Aparecido dos. Nem crime, nem castigo: o racismo na percepção do judiciário e das vítimas de atos de discriminação. Revista do Instituto de Estudos Brasileiros, Brasil, $\mathrm{n}$. 62, p. 184-207, dez. 2015.

SCHWARCZ, Lilia. O espetáculo das raças. Cientistas, instituições e a questão racial no Brasil. 1870-1930. São Paulo: Companhia das Letras, 1993.

SKIDMORE, Thomas. Preto no Branco. Raça e nacionalidade no pensamento brasileiro. Rio de Janeiro: Paz e Terra, 1976.

SILVA, Vagner Gonçalves. Candomblé e Umbanda. Caminhos da devoção brasileira. São Paulo: Selo Negro, 2005.

TELLES, Edward. Racismo à Brasileira. Uma nova perspectiva sociológica. Rio de Janeiro: Relume Dumará, 2003.

VERGER, Pierre. Lendas dos Deuses Africanos. Bahia: Corrupio, 1992. 